Please do not remove this page

RMIT

UNIVERSITY

\title{
Electro-deposition of gold nano-structures on gold Quartz Crystal Microbalance (QCM) electrodes for enhanced mercury vapour sensitivity in the presence of interferent gasses
}

Sabri, Ylias; Ippolito, Samuel; Tardio, James; Sood, Dinesh; Bhargava, Suresh

https://researchrepository.rmit.edu.au/esploro/outputs/9921864044801341/filesAndLinks?institution=61RMIT_INST\&index=null

Sabri, Y., Ippolito, S., Tardio, J., Sood, D., \& Bhargava, S. (2008). Electro-deposition of gold nano-structures on gold Quartz Crystal Microbalance (QCM) electrodes for enhanced mercury vapour sensitivity in the presence of interferent gasses. Proceedings of ICONN 2008, 71-74.

https://doi.org/10.1109/ICONN.2008.4639248

Published Version: https://doi.org/10.1109/ICONN.2008.4639248

Repository homepage: https://researchrepository.rmit.edu.au

(c) 2008 IEEE. Personal use of this material is permitted. However, permission to reprint/republish this material for advertising or promotional purposes or for creating new collective works for resale or redistribution to servers or lists, or to reuse any copyrighted component of this work in other works must be obtained from the IEEE.

Downloaded On 2023/04/26 11:48:58 +1000 


\title{
Electro-deposition of Gold Nano-Structures on Gold Quartz Crystal Microbalance (QCM) Electrodes for Enhanced Mercury Vapour Sensitivity in the Presence of Interferent Gases
}

\author{
Ylias M. Sabri, Samuel J. Ippolito, James Tardio, Dinesh K. Sood and Suresh K. Bhargava \\ ${ }^{1}$ Industrial Chemistry Group, School of Applied Sciences, RMIT University, Melbourne, Australia 3001 \\ Email: ylias.sabri@student.rmit.edu.au \\ Telephone: (+61 3) 9925 3365, Fax: (+61 3) 99253365
}

\begin{abstract}
Gold electrode Quartz Crystal Microbalances (QCMs) were used as transducing platform to detect and sense elemental mercury $(\mathrm{Hg})$ in gas phase. The enhanced sensitivity, resulting form the electro-deposition of gold nano-structures on the surface is shown to increase the response magnitude (RM) of the sensors in the presence of ammonia and humidity interference. The concentration of $\mathrm{NH}_{3}$ and $\mathrm{H}_{2} \mathrm{O}$ was varied in the range 590 to $1770 \mathrm{mg} / \mathrm{m}^{3}$ and 4.2 to $10.4 \mathrm{mg} / \mathrm{m}^{3}$, respectively. A constant gas flow of $200 \mathrm{sccm}$, balanced in nitrogen was used as the carrier gas. The RM for $\mathrm{Hg}$ was enhanced by creating nanostructures on the sensor's gold electrodes via electro-deposition of gold in a lead acetate electrolyte. The results presented are a critical step in the development of a cheap regenerable and reliable sensor for measuring $\mathrm{Hg}$ in the presence of interferents gases commonly found in industrial applications.
\end{abstract}

Keywords - Electro-deposition, QCM, gold, mercury-sensing, ammonia, humidity, interference.

\section{INTRODUCTION}

Quartz crystal microbalances (QCMs) have gained a considerable interest for gas phase sensing [1,2] due to their stability, robust nature and simple operation. In 1959, Sauerbrey showed [3] that for an ideal layer of foreign mass deposited on the active surface of a QCM, a measurable change in frequency $(\Delta \mathrm{f})$ is proportional to the deposited mass $(\Delta \mathrm{m})$ on the surface, if the resonator is operated in air or vacuum:

$$
\Delta f=-\frac{2 f_{0}^{2}}{A \sqrt{c_{66} \rho_{q}}} \Delta m=-S_{f} \Delta m
$$

where $S_{f}$ represents the integral mass sensitivity or Sauerbrey constant and is proportional to the square of the fundamental frequency, $\mathrm{f}_{0}$. The active surface area is denoted by $A$ and $C_{66}$ and $\rho_{q}$ are material properties of the quartz crystal.

It is well understood from the literature that $\mathrm{Hg}$ adsorbs on to $\mathrm{Au}[4,5]$ and forms an amalgam over time [6]. For mercury vapor sensing purposes, it is important to obtain a high sensitivity when using a QCM in the presence of interferent gas species. Increasing the active surface area of the QCM electrode is thought to reduce the required exposure time of the sensor towards $\mathrm{Hg}$ vapor. The reduced exposure decreases the amount of $\mathrm{Hg}$ amalgamation, increasing the QCM's ability to regenerate itself by desorbing most of the adsorbed $\mathrm{Hg}$ at the conclusion of the sensing process.

In this work, the mass sensitivity of a QCM was improved by increasing the surface area of the gold electrodes via electrodeposition of nanostructure $\mathrm{Au}$, using a process similar to that of Noort et. al. [7] and Imamura et. al. [8]. With this method, we have achieved approximately two to three times larger response magnitude (RM) towards $\mathrm{Hg}$ than non-modified $\mathrm{Au}$ QCM electrodes. These nano structures are shown to enhance the signal for $\mathrm{Hg}$ sensing, even in the presence of interfering gases such as ammonia and humidity.

\section{PREPARATION OF QCM CRYSTALS}

The two electrodes on either side of the quartz crystal were fabricated with a 100nm thin film of gold deposited over a $10 \mathrm{~nm} \mathrm{Ti}$ adhesion layer by e-beam evaporation. A nonmodified crystal served as a control, while several others were set aside for surface modification by electro-deposition.

The electro-deposition was performed using an electrolyte solution containing $27.18 \mathrm{~g} / \mathrm{L}$ hydrogen tetrachloroaurate (III) hydrate and $1.77 \mathrm{~g} / \mathrm{L}$ lead(IV) acetate (from Sigma-Aldrich, Australia). A potential of $-2 \mathrm{~V}$ was applied between the two electrodes of the crystal (Cathode) and Au foil (anode) for $30-$ 120s. This insured that $\mathrm{Au}$ nano-structures were formed on both Au electrodes of the QCM.

\section{EXPERIMENTAL PROCEDURE}

The QCMs were used as the frequency determining element in an oscillator circuit. An Agilent (53131A) frequency counter was used to measuring the resonant frequency change. A constant flow rate of $200 \mathrm{sccm}$ during all stages of testing was provided by a specially developed 4 channel mass flow controller system, while data acquisition was performed via a conventional desktop computer. The different $\mathrm{Hg}$ concentrations were generated by controlling the permeation tube temperature (P/N 137-100-0030-S56-C90), which were 
purchased from VICI AG International, TX, USA. The $\mathrm{Hg}$ concentrations were calibrated using $\mathrm{KMnO}_{4}$ (Sigma Aldrich, Vic, Aust.) trapping method and analyzed by ICPMS (Inductively coupled plasma mass spectroscopy). The three $\mathrm{Hg}$ concentrations the sensors were tested towards were $3.65,5.70$ and $10.55 \mathrm{mg} / \mathrm{m}^{3}$. The interferents were tested by introducing the interferent species to the sensors at all times during and after $\mathrm{Hg}$ exposures. The chamber temperature was maintained constant at $55^{\circ} \mathrm{C}$.

\section{RESULTS AND DISCUSSION}

Upon experimenting with the time of electro-deposition, the optimum time was found to be 30 s providing the highest Quality - factor for the QCM transducer. Higher electrodeposition times were found to increase the loss of energy and so stop the oscillation of the QCM. Figure 1 and 2 show both the Secondary Electron Microscope (SEM) and Atomic Force Microscope (AFM) images of the non-modified and modified via electro-deposition Au electrode surfaces after exposure to mercury, ammonia and humidity.

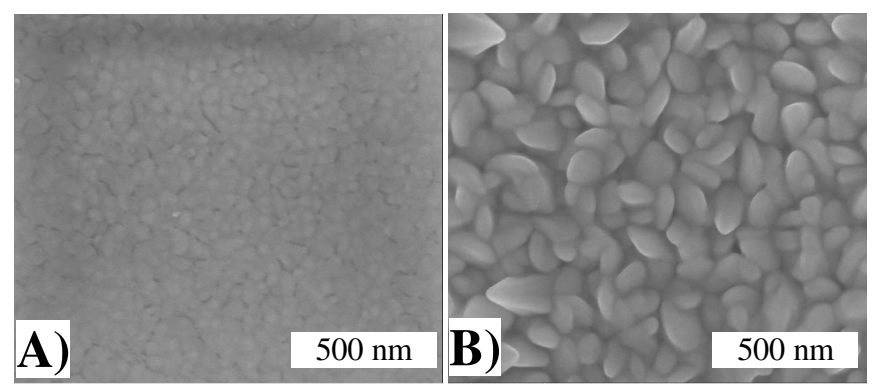

Figure 1. SEM images of A) Non-modified suface after exposure to $\mathrm{Hg}$ and B) Electrodeposited suface after exposure to $\mathrm{Hg}$



A) $\begin{aligned} & X 0.5 \mu \mathrm{m} / \mathrm{div} \\ & Z 50 \mathrm{~nm} / \mathrm{div}\end{aligned}$



B) $X 0.5 \mu \mathrm{m} / \mathrm{div}$ $\mathrm{Z} 200 \mathrm{~nm} / \mathrm{div}$
Figure 2. AFM images of A) Non-modified suface after exposure to $\mathrm{Hg}$ and B) Electrodeposited suface after exposure to $\mathrm{Hg}$

The SEM images confirm the growth of nano-structure grains of around 50 to $250 \mathrm{~nm}$ in size, after electro-deposition. The electro-deposited structures (Fig.1B) seemed to be coming out of the surface while the polished surface (Fig. 1A) seemed to have similar but smaller sized grains compared to the electro-deposited film. These "bead" type structures are about 20 to $50 \mathrm{~nm}$ in size. AFM characterization (Fig. 2) of same surfaces indicates that the mean roughness is increased by a factor of 11.5 between the electro-deposited and non-modified surfaces, resulting in a $45 \%$ increase in surface area after electro-deposition.

The fundamental frequencies of the modified QCM, before and after the electro-deposition process, were logged. From these data, using equation 1 , it was found that the $\mathrm{Au}$ deposited on the QCM Au electrode was approximately $887 \mu \mathrm{g} / \mathrm{cm}^{2}$. It is illustrated from figure 3 that the surface physical state has not changed significantly compared to the non-modified QCM Au electrode.

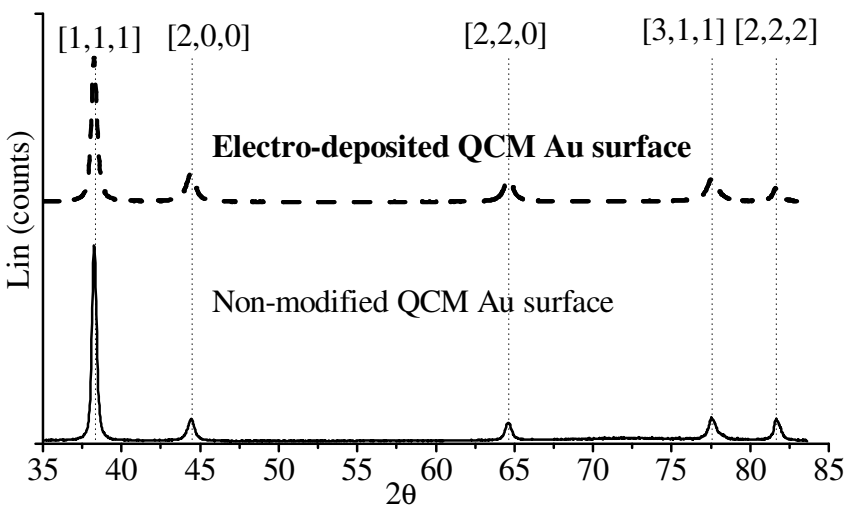

Figure 3. XRD specta of Non-modified suface (line, bottom) and Electrodeposited suface (dashed, top)

Both the non-modified and electro-deposited $\mathrm{Au}$ surfaces were then exposed to $\mathrm{Hg}$. The dynamic responses of the two QCMs are shown in figure $3 \mathrm{~A}$ and $3 \mathrm{~B}$. The results illustrate that the modification via electro-deposition has increased the QCM affinity for $\mathrm{Hg}$ compared to the non-modifed QCM.
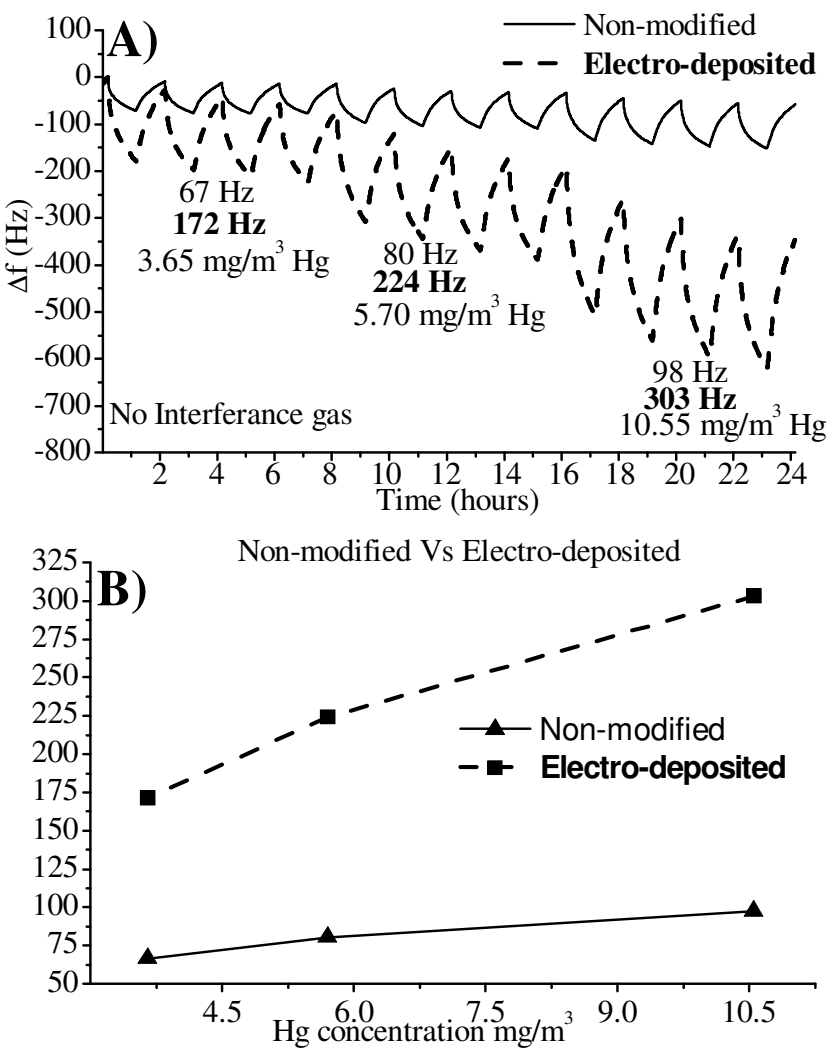

Figure 4. Dynamic response of non-modified (line) and Electro-deposited (dashed) sensors towards $\mathrm{Hg} \mathrm{A}$ ) in nitrogen, and B) Response magnitude of Non-modified (line, triangles) and electro-deposited (dashed, squares) exposed to varying concentrations of mercury 
It is well known that sensitivity is analyte concentration dependent $[9,10]$. The sensitivity of the electro-deposited device is shown to be 157,180 and $212 \%$ larger than the nonmodified for the three tested concentrations of 3.65, 5.70 and $10.55 \mathrm{mg} / \mathrm{m}^{3} \mathrm{Hg}$, respectively. Thus, it appears that the electrodeposited sensor operates in a different non linear region than that of the non-modified QCM. One would expect that due to the increased surface area of $45 \%$ from AFM data, we would expect a $45 \%$ increase in the mass adsorbed on the gold surface. From Sauerbrey equation, since $\Delta \mathrm{f}$ is proportional to $\Delta \mathrm{m}$, a $45 \%$ increase in $\mathrm{RM}$ towards pure $\mathrm{Hg}$ of any concentration would be expected. Therefore the increase in response is not purely due to surface area increase reported by AFM. It is thought that electro-deposition process may have developed greater number of grain boundaries and defects. This assumption could then agree with the proposal of George et al [11] that the rougher film substrates promote diffusion of mercury into the films' grain boundaries. The non-modified sample is simply gold on polished quartz with $\mathrm{Ti}$ as the adhesion layer and is a film that is very flat and contains uniform grains and compact grain boundaries. Therefore, there are fewer sites available for mercury to occupy on the nonmodified sample and hence a smaller RM is observed.

Even though the response of the electro-deposited QCM drifts down significantly compared to the non-modified QCM, the $\mathrm{RM}$ of the electro-deposited sensor was more repeatable over the four pulses for each concentration of $\mathrm{Hg}$ in figure $4 \mathrm{~A}$ (within $+/-0.6 \%$ ) than the non-modified sensor (within $+/-$ $1.7 \%)$. From here on, only the results from the electrodeposited QCM is reported since it is found to be much superior in terms of response and repeatability over the nonmodified QCM.

The modified sensor was tested against $\mathrm{Hg}$ in the presence of humidity $\left(4.2\right.$ and $\left.10.4 \mathrm{mg} / \mathrm{m}^{3}\right)$ acting as one of the main interferent gas (figure 5). It was found that the effect of humidity rises with increasing $\mathrm{Hg}$ concentrations. At a humidity concentration of $4.2 \mathrm{mg} / \mathrm{m}^{3}$ and a $\mathrm{Hg}$ concentration of $3.65 \mathrm{mg} / \mathrm{m}^{3}$, the RM of the electro-deposited sensor decreased by $5.9 \%$ leading to the sensor reporting $5.9 \%$ lower concentration.

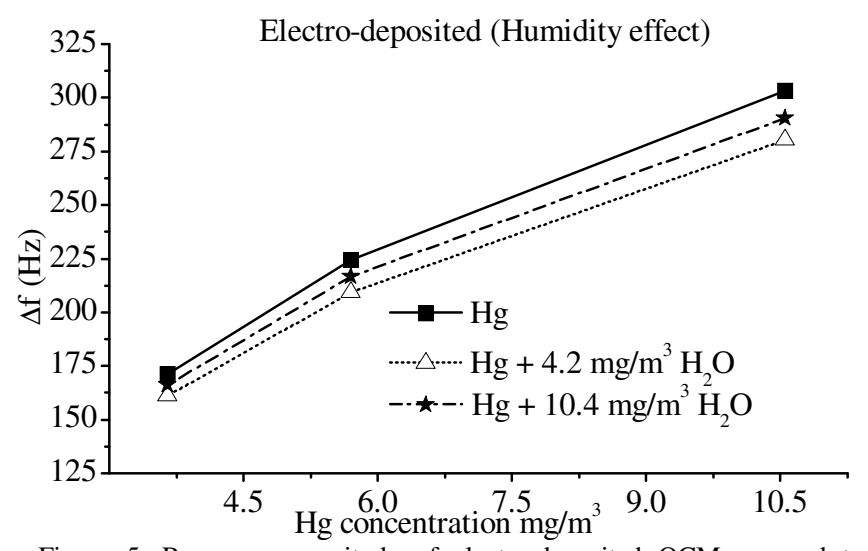

Figure 5. Response magnitude of electro-deposited QCM exposed to varying concentrations of mercury and humidity

It is noted that a larger drop in $\mathrm{RM}$ occurs due to the $\mathrm{NH}_{3}$ interferent (figure 6). That is, at $\mathrm{Hg}$ concentration of
$3.65 \mathrm{mg} / \mathrm{m}^{3}$ and ammonia concentration of $590 \mathrm{mg} / \mathrm{m}^{3}$, the electro-deposited surface had dropped $17 \%$ in RM. At the higher ammonia concentration of $1770 \mathrm{mg} / \mathrm{m}^{3}$, the drop in RM increases to $21 \%$.

While keeping ammonia at $1770 \mathrm{mg} / \mathrm{m}^{3}$ and increasing the $\mathrm{Hg}$ concentration, the reduction in RM seems to decrease by $17.5 \%$. It was also observed that the reduction in response magnitude does not reduce with decreasing ammonia concentration.

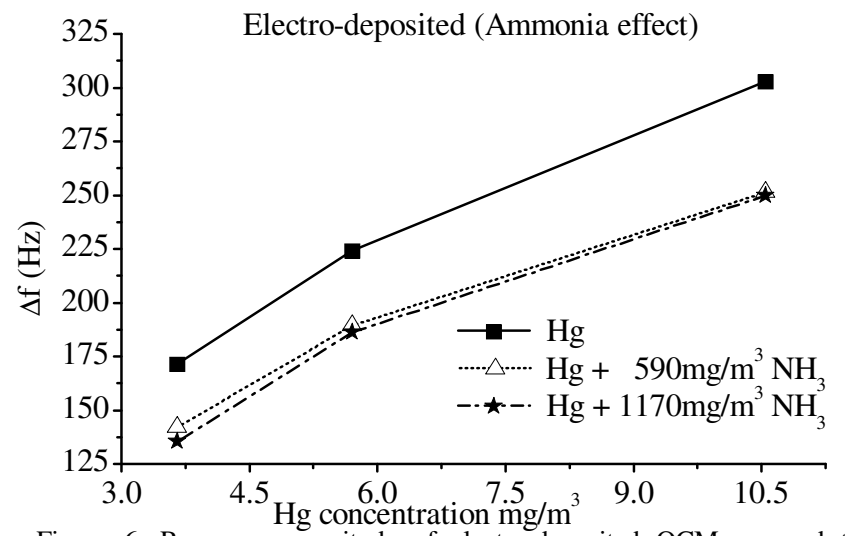

Figure 6. Response magnitude of electro-deposited QCM exposed to varying concentrations of mercury and ammonia

By examining the response of electro-deposited sensor from figures 5 and 6 , we observe that ammonia exposure had a bigger RM reduction affect as compared to humidity. This behavior may be explained from the work of Bilic et al. [12] who have reported high adsorption energy of ammonia on the $\mathrm{Au}$ (111) surface. They suggest the absence of covalent bonding between the gold and ammonia and suggest that the interaction is dispersive with some contribution from polarization. In their work, Kay et al. [13] studied the influence of adsorbate-absorbate hydrogen bonding of $\mathrm{NH}_{3}$ and $\mathrm{H}_{2} \mathrm{O}$ on $\mathrm{Au}$ (111) and stated that repulsive interactions occur between acidic hydrogen atoms on adjacent $\mathrm{NH}_{3}$ molecules and that $\mathrm{H}_{2} \mathrm{O}$ binds more strongly to itself than to the $\mathrm{Au}$ substrate. Their observation explains the reasoning behind greater reduction in RM of the $\mathrm{Au}$ electrode QCM sensors upon exposure of ammonia over humidity. Water molecules are easily desorbed, from $\mathrm{Au}$ and its bound counterpart $\mathrm{H}_{2} \mathrm{O}$ molecules, off to the nitrogen atmosphere whereas $\mathrm{NH}_{3}$ molecules are more strongly bound to the $\mathrm{Au}$ substrate. Therefore it can be assumed that ammonia is not desorbed from the surface to the extent of humidity desorption and therefore the ammonia may work as a barrier for further $\mathrm{Hg}$ to adsorb on the surface resulting in reduced RM. Surface-enhanced Raman spectroscopy (SERS) study have been used in the past to show that even though ammonia does adsorb on gold, no irreversibly adsorbed ammonia species are formed at the gold electrode [14]. Therefore, ammonia is expected to completely desorb from the gold surface in the recovery period where only nitrogen gas is allowed in the sensing chamber.

In the final stage of the experiment, the electro-deposited sensor was exposed to $\mathrm{Hg}$ in the presence of both $\mathrm{H}_{2} \mathrm{O}$ and $\mathrm{NH}_{3}$ interferents. The QCM responses are presented in figure 7 below. It is observed that once an exposure of an interferent mixture occurs and reduces the RM of the modified sensor 
towards $\mathrm{Hg}$, no further reduction is observed when different concentrations of interferent mixtures are exposed. Upon the exposure of $\mathrm{Hg}$ in the presence of mixed interferents for the first time, the electro-deposited sensor reduced in RM by $21 \%$. This is similar to the reduction observed when exposing only ammonia as the interferent gas (figure 6), indicating again that most if not all reduction in RM occurs due to ammonia.



Figure 7. Response magnitude of electro-deposited QCM exposed to varying concentrations of mercury, humidity and ammonia

After the initial interferent exposure cycle, further exposures at different interferent concentrations only gave an error of $2.4 \%$ for the electro-deposited QCM. This suggests that the Au electrode surfaces reaches equilibrium and becomes stable towards interferents. That is, once the sensors are calibrated against different concentrations of $\mathrm{Hg}$ in the presence of interferent gases mentioned, an error of $\sim 2.4 \%$ would be expected from there on in, due to the fluctuations of interferents concentration in the application of an online $\mathrm{Hg}$ sensor.

\section{CONCLUSION}

The electro-deposited sensor was observed to have significantly larger response magnitude towards gaseous elemental mercury than the non-modified sensor. The sensitivity increase of the electro-deposited sensor was found to be $\mathrm{Hg}$ concentration dependent and so it appeared that the electro-deposited sensor operated in a different non linear region than that of the non-modified QCM. However, a drift in the response of the electro-deposited sensor was observed. The sensors were found to be more stable towards humidity, than ammonia as interferents while sensing gaseous elemental $\mathrm{Hg}$. Ammonia as an interferent reduces the QCMs response magnitude by $21 \%$. No significant further reduction in response magnitude upon exposure of $\mathrm{NH}_{3}$ and $\mathrm{H}_{2} \mathrm{O}$ interferents was observed following the first exposure of Ammonia, even when both interferents were present simultaneously. Experiments are under way to optimize the electro-deposition parameters in order to further develop the sensitivity and stability of the electro-deposited QCM towards $\mathrm{Hg}$.

\section{ACKNOWLEDEMENTS}

The authors thanks Alcoa World Alumina, BHP Billiton and the Australian Research Council (ARC) for their financial support through an ARC-Linkage (Project ID: LP0455264) to undergo this study.

\section{REFERENCES}

[1] T. Nakamoto, Y. Suzuki, T. Moriizumi, "Study of VHF-band QCM gas sensor," Sensors and Actuators B, 84, pp. 98 - 105, 2002.

[2] B. Ding, J. Kim, Y. Miyazaki, S. Shiratori, "Electrospun nanofibrous membranes coated quartz crystal microbalance as gas sensor for $\mathrm{NH}_{3}$ detection," .Sensors and Actuators B, 101, pp. 373 - 380, 2004.

[3] G. Sauerbrey, "The use of quartz oscillator for weighing thin layers and for microweighing," zeitschrift fuer physik, vol. 155, pp. 206-222, 1959.

[4] T. Morris, J. Sun, G. Szulczewski, "Measurement of the chemical and morphological changes that occur on gold surfaces following thermal desorption and acid dissolution of adsorbed mercury," Analytica Chimica Acta, 469, pp. $279-287,2003$

[5] P. S. Waggoner, H.G. Craighead, "Micro- and nanomechanical sensors for environmental, chemical, and biological detectrion," The Royal Society of Chemistry, 7, pp. 1238 - 1255, 2007.

[6] R. Nowakowski, T. Kobiela, Z. Wolfram, R. Dus, "Atomic force microscopy of $\mathrm{Au} / \mathrm{Hg}$ alloy formation on thin Au films," App. Surf. Sci., vol. 115, pp. 217-231, 1997.

[7] D. Noort, R. Rani, C. Mandenius, "Improving the sensitivity of a Quartz crystal microbalance for biosensing by using porous gold," Mikrochim. Acta., 136, pp. 49-53, 2001.

[8] M. Imamura, T. Haruyama, E. Kobatake, Y. Ikariyama, M. Aizawa, "Selfassembly of mediator-modified enzyme in porous gold-black electrode for biosensing," Sensors and Actuators B, 24 - 25, pp. 113 - 116, 1995.

[9] H. Bohets, K. Vanhoutte, R. D. Maesschalck, P. Cockaerts, B. Vissers, L. J. Nagels, "Development of in situ ion selective sensors for dissolution," Analytica Chimica Acta, 581, pp. 181 - 191, 2007

[10] L. C. Brousseau, III, T.E. Mallouk, "Molecular design of intercalationbased sensors. 1. Ammonia sensing with quartz crystal microbalances modified by copper biphenylbis(phosphonate) thin films," Analytical Chemistry, 69(4), pp. 679 - 687, 1997.

[11] M. A. George, W. S. Glaunsinger, "The electrical and structural properties of gold films and mercury-covered gold films," Thin Solid Films, 245 , pp. $215-224,1994$.

[12] A. Bilic and J. R. Reimers, "Adsorption of ammonia on gold (111) surface,” J. Chem. Phys., vol. 116(20), pp. 8981 - 8987, May 2002.

[13] B. Kay, K. Lykke, J. Creighton and S. Ward, "The influence of adsorbate-absorbate hydrogen bonding in molecular chemisorption: NH3, HF and H2O on Au(111)," vol. 91(8), pp. 5120 - 5121, June 1989.

[14] A. C. A. De Vooys, M. F. Mrozek, M. T. M. Koper, R. A. Van Santen, J. A. R. Van Veen, M. J. Weaver, "The nature of chisorbates formed from ammonia on gold and palladium electrodes as discerned from surfaceenhanced Raman spectroscopy," Electrochemistry Communications, 3, pp. 293 - 298, 2001. 